\title{
CRICOTOPUS (S. STR.) LATELLAI SP. N., A NEW RHEOPHILIC SPECIES OF THE tremulus-Group from the Italian ANd French Maritime Alps (Diptera: Chironomidae)
}

\author{
Joel Moubayed-Breil ${ }^{1}$ and Patrick Ashe ${ }^{2}$ \\ ${ }^{1}$ Consultant in Freshwater \& Marine Biology, 10 rue des Fenouils, F-34070 Montpellier, France. \\ Email: joelmb34@free.fr, corresponding author \\ ${ }^{2} 33$ Shelton Drive, Terenure, Dublin 12, Ireland.Email: patrick.ashe1983@gmail.com \\ http://zoobank.org/4B55C4D5-9ADC-4BF9-B836-57DC3CB27F89
}

\begin{abstract}
Cricotopus (Cricotopus) latellai $\mathrm{sp} . \mathrm{n}$. is described and diagnosed based on material comprising male and female pharate adults, pupal exuviae and larvae recently collected in some glacial streams in both the Italian and French Maritime Alps. Taxonomic notes provided in this paper include: description of C. latellai sp. n. as male and female adults, pupal exuviae and last instar larvae. The diagnosis of the Cricotopus tremulus-group is supplemented with additional characters in the male adult and pupal exuviae. Cricotopus latellai sp. n. keys near $C$. mantetanus Moubayed-Breil, 2016 and C. storozhenkoi Makarchenko \& Makarchenko, 2016. Geographical distribution of $C$. latellai sp. n. is currently restricted to the Italian and French Maritime Alps. It belongs to the Tyrrhenian community of glacial relic species, which are considered to be indicators of climate change in this biogeographical region. Remarks, taxonomic position, and ecology of the new described species are given.
\end{abstract}

\section{Introduction}

Data on the taxonomy, geographical distribution and ecology of the tremulus-group of the genus Cricotopus v. d. Wulp, 1874 from the Palaearctic (Hirvenoja 1973; Sæther 1977; Coffman et al. 1986; Moubayed \& Hirvenoja 1986; Cranston et al. 1989; Casas \& Vilchez-Quero 1992; Ashe \& O’Connor 2012; Lencioni et al. 2012; Andersen et al. 2013; Sæther \& Spies 2013; Makarchenko \& Makarchenko 2016; Moubayed-Breil \& Ashe 2011, 2016) shows that six valid species are currently known including two from the Russian Far East (C. leleji Makarchenko \& Makarchenko, 2016 and $C$. storozhenkoi Makarchenko \& Makarchenko, 2016) and four from Europe: C. mantetanus Moubayed-Breil, 2016; C. nevadensis Casas \& Vilchez-Quero, 1992; C. royanus MoubayedBreil, 2016 and C. tremulus (Linnaeus, 1758). In this paper, a seventh new species (C. latellai $\mathrm{sp} . \mathrm{n}$.) is described based on associated pharate material comprising male and female adults, pupal exuviae and larvae collected in glacial streams located in northwest Italy in the dolomitic upstream area of the Po River Basin in the Alpi Marittime at an altitude 1500-1750 $\mathrm{m}$ and in southeast France in the karstic upstream area of the Roya River Basin in the Maritime Alps at an altitude of 1500-1750 m.

\section{Methods}

Morphological terminology and measurements follow that of Sæther (1980) for the imagines and pupal exuviae. For a better examination of the specific features and more accurate description of the various taxonomic details of the pupa, the pupal abdomen was mounted not only in dorsal and ventral view but separately in lateral view, which facilitates proper examination and illustration of all the relevant taxonomic characters. Remarks and discussion on some related species and comments on the ecology and geographical distribution of the new species are given.

\section{Results}

Cricotopus latellai sp. n. belongs to the tremulusgroup based on characters found in the male adult (distribution pattern of median setae on tergites II$\mathrm{V}$; shape of tergite IX, inferior volsella and gonostylus) and pupal exuviae (chaetotaxy and granulation of thorax; armament of abdominal segments, shape and size of anal macrosetae) and keys near C. mantetanus and C. storozhenkoi. The new species is only known from high and middle mountain streams located in both the Italian and French Maritime Alps. The 766 valid species known from continental France (Moubayed-Breil \& Ashe own observations, Moubayed-Breil 2016) increases to 767 with the description of a new species of Propsilocerus Kieffer from eastern France (MoubayedBreil, in press). Consequently, the description of C. latellai sp. n. increases the total number to $\mathbf{7 6 8}$ species known from continental France. 
The tremulus-group was first emended by Hirvenoja (1973) then modified by Moubayed \& Hirvenoja (1986), Casas \& Vilchez-Quero (1992) and most recently by Moubayed-Breil (2016). The diagnosis of the tremulus-group is refined by including features found in the male adult and pupal exuviae:

Adult male. Palpomere 3 with 2-3 sensilla coeloconica placed distally; presence of lateral and occasionally median antepronotals; apex of femur and base of tibia of fore-, mid-, and hind leg blackish; tergites I-II whitish, remaining tergites blackish; chaetotaxy and distribution pattern of setae on median part of tergites II-V; gonocoxite with rounded or truncated apex, bearing or lacking a sub-triangular to rounded setiferous projection placed dorsally close to base of inferior volsella; inferior volsella: (i) pointing downwards at an acute angle, narrow and finger-like ( $C$. nevadensis), (ii) a projecting lobe with outer margin gradually bent downwards and lacking strong dorsal setae on outer edge (C. latellai, $C$. royanus and $C$. tremulus), (iii) a projecting lobe with outer margin abruptly bent downwards at a right angle and with 2 strong dorsal setae on outer edge (C. mantetanus); crista dorsalis medium to large, toothlike, with pointed or rounded apex, moderately to strongly projecting orally.

Pupal exuviae. Colouration brownish or contrasting whitish to blackish; frontal apotome with wrinkles and granulation, occasionally domed, frontal setae inserted on prefrons, ventral to antennal sheaths; cephalothorax with moderate to dense wrinkles and granulation, bearing or lacking a transverse posteromedian blackish shading placed between the thoracic suture $\left(\mathrm{Dc}_{3}\right.$ and $\left.\mathrm{Dc}_{4}\right)$ and base of wing sheath, dorsocentrals are all setaelike or include 1-2 bristle-like setae; thoracic horn tube-like, foliate to ellipse-shaped with or without narrowing apex, toothed in general, occasionally smooth, teeth are pointed or occasionally smooth; anterior and posterior fields of spines on tergites III-VI clearly separated; median field of spines on tergite VI circular, diamond-like to sub-oval, posterior area of sternites V-VI with or without a faint transverse median patch of spines which, when present, are more concentrated and markedly larger on VI; anal lobe with distal part narrowing or distinctly swollen, apical rows of small spines restricted to apical area or extending well above insertion of anal macrosetae; macrosetae short and pin-like with a slightly curved apices.

\section{Description}

Cricotopus latellai Moubayed-Breil \& Ashe, sp. n.

http://zoobank.org/125F054A-DCD5-4F0A8AF3-5553C1A32B0A

\section{Material examined}

Holotype. Italy, Alpi Marittime. Po River Basin, upstream, rapid to moderate rhithral and waterfalls,

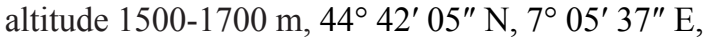
11.VII.2017; 1 male pharate adult, leg. J. Moubayed-Breil and P. Ashe. Environmental data of water: moderately crystalline, conductivity about 20-30 $\mu \mathrm{S} / \mathrm{cm}$; temperature $8-12{ }^{\circ} \mathrm{C}$.

Paratypes. Italy, Alpi Marittime. Adults (5 males, 2 females); pharate adults (2 males, 2 females); pupal exuviae (10 males, 15 females); 3 larvae; same locality and date as for holotype. Continental France, Maritime Alps, Casterino stream, a tributary of the Roya River, alt. 1500-1700 m, $44^{\circ} 4^{\prime} 34^{\prime \prime} \mathrm{N}, 7^{\circ} 26^{\prime} 18^{\prime \prime}$ E, 22.VI.2016; pupal exuviae (1 male and 2 females); leg. J. MoubayedBreil. Environmental data of water are: calcareous water, conductivity $95-100 \mu \mathrm{S} / \mathrm{cm}$; temperature $8-12{ }^{\circ} \mathrm{C}$ during late spring and summer.

Holotype (on 2 slides, including the male adult and its pupal exuviae) with 1 additional paratype are deposited in the collections of the Zoologische Staatssammlung München (ZSM), Munich, Germany. Remaining paratypes are deposited in the senior author's collection. Type material was preserved in $80-85 \%$ alcohol, and later mounted in polyvinyl lactophenol. For each adult, the head, thorax and abdomen were cleared in 90\% lactic acid then washed in about $60 \%$ ethanol before mounting on slides.

\section{Diagnostic characters}

Based on similarity of characters found in the male adult and pupal exuviae of the tremulus-group, three species (C. latellai sp. n., C. mantetanus and C. storozhenkoi) are considered to be sister species. However $C$. latellai sp. n. can be easily separated with the following characters:

Male adult: palpomere 3 with 2 sensilla coeloconica (tubule-like) placed distally; tergites III-IV with 3 median setae placed distally; laterosternite VIII not lobe-like; inferior volsella consists of a projecting lobe-like, with rounded outer margin gradually bent downwards, posterior area bearing two minute lobes, with a distinct rounded setiferous lobe placed close to its base; crista dorsalis large, tooth-like and orally projecting, apex rounded in dorsal view and pointed in lateral view; 
Pupal exuviae: thoracic horn foliate to ellipselike, narrowing distally with pointed to smooth ending apically, toothed, teeth are smooth in general or occasionally weekly pointed; tergite VI with median dorsal field of spines semi-circular to diamond-like; posterior area of sternite VI with a distinct median patch of spines; distal part of anal lobe narrowing, apical rows of small spines extending well above insertion of anal macrosetae; macrosetae short with markedly curved apices.

Etymology: The new species is named 'latellai' after our colleague Dr. Leonardo Latella, curator of zoology at the Museum of Natural History of Verona (Italy), who is contributing to preserve the biological and ecological quality of water and environment in Verona and surrounding areas.

\section{Male adult}

$(\mathrm{n}=7: 2$ pharate adults +5 adults; Figs $1-4,7-11$, 13-15)

Medium to large sized Cricotopus species. Total length 3.50-4.00 mm. Wing length 2.20-2.40 mm; $\mathrm{TL} / \mathrm{WL}=1.60-1.70$. General colouration contrasting blackish to brownish to yellowish with black mesonotal stripes. Head dark brown, antennae pale brown, thorax brown to dark brown, mesonotal stripes distinctly blackish; wing pale to pale brown. Legs mostly yellowish brown to dark brown, only base of femur and base and apex of tibia of PI-PIII blackish. Tergites I-II whitish, tergites III-VIII entirely brownish to blackish, anal segment contrasting brown to dark brown.

Head. Eyes hairy, inner eye margin bare. Temporals consist of 8 uniserial setae including 5 inner and 3 verticals. Clypeus trapezoidal to sub-square shaped with 14-16 setae placed in 4 rows. Palp 5-segmented; first and second palpomeres fused; length $(\mu \mathrm{m})$ of segments 40, 70, 120, 135, 195; palpomere 3 with 2 sensilla coeloconica (tubule-like) inserted in a circular depression placed on distal part (Fig. 1). Antenna 900-930 $\mu \mathrm{m}$ long, 13-segmented; antennal groove beginning on segments 3-4 and reaching ultimate flagellomere; ultimate flagellomere 400-430 $\mu \mathrm{m}$ long, distinctly clubbed and bearing a brush of curved sensilla chaetica apically. AR 0.80-0.85.
Thorax. Lobes of antepronotum gaping, with 3 median and 3-4 antepronotals which are slightly indistinct; acrostichals 29-31 uni-biserial, dorsocentrals, 16-18 multiserial and converging medially, prealars 3-4. Scutellum with 10 setae in a single row. Wing. Brachiolum with 1 seta. Number of setae on veins: R, 3-5; remaining veins bare. Squama with 14-16 setae in a single row. Legs. Tarsomere $\mathrm{ta}_{5}$ of PI, PII and PIII distinctly shorter than $\mathrm{ta}_{4}$. Sensilla chaetica densely present on tarsomeres ta to ta ${ }_{5}$ of PI, PII and PIII. Length $(\mu \mathrm{m})$ and proportions of legs (Table 1).

Abdomen. Dorsal margin of tergite IX sinuous with a distinct median lobe (Fig. 2); posterior margin broadly bilobed (Figs 3, 7); presence of 17-20 dorsal setae placed in 2 rows (7-8 anteriorly, 10-12 posteriorly). Laterosternite IX with 4 setae ( 2 on each side), extended vertically and lacking lateral lobe-like expansions on each side. Anal point absent. Sternapodeme and phallapodeme as in Fig. 8, transverse sternapodeme orally produced and arclike; phallapodeme markedly sickle shaped. Distribution pattern of setae on median area of tergites II-V as illustrated (Fig. 4): tergite II (2 setae distally); III-IV (3 setae distally); V (4 setae, 2 anteriorly and 2 distally). Hypopygium in dorsal, ventral and lateral view as in Figs 7-11, 13-15, ventral view (Fig. 8) with tergite IX removed. Gonocoxite 250$260 \mu \mathrm{m}$ long, apex rounded in dorsal view (Fig. 7) and distinctly truncate in lateral view (Fig. 13); inferior volsella hyaline, long lobe-like, projecting with rounded outer margin gradually bent downwards, wider at base and broadly narrowing distally to a rounded apex, presence of two minute lobes on posterior part which are clearly visible in lateral view (Fig. 13), presence of 5-6 small setae on dorsal area. Gonostylus (Figs 10-11, 15) 120-130 $\mu \mathrm{m}$ long, narrowing distally to a pointed apex; posterior margin rounded medially in dorsal view (Figs 10-11), distinctly sinuous in lateral view (Fig. 15), anterior margin concave medially with an orally directed triangular projection clearly visible in lateral view (Fig. 15); 2 orally directed strong setae are placed close to the megaseta. Crista dorsalis (Figs 10-11, 15) large, tooth-like and orally projecting, apex rounded in dorsal view (Figs 1112) and sharply pointed in lateral view (Fig. 15). Megaseta 18-21 $\mu \mathrm{m}$ long and slender.

Table 1. Cricotopus latellai sp. n. Length $(\mu \mathrm{m})$ and proportions of legs.

\begin{tabular}{cccccccccccc}
\hline & $\mathbf{f e}$ & $\mathbf{t i}$ & $\mathbf{t a}_{\mathbf{1}}$ & $\mathbf{t a}_{\mathbf{2}}$ & $\mathbf{t a}_{\mathbf{3}}$ & $\mathbf{t a}_{\mathbf{4}}$ & $\mathbf{t a}_{\mathbf{5}}$ & $\mathbf{L R}$ & $\mathbf{B V}$ & $\mathbf{S V}$ & $\mathbf{B R}$ \\
\hline PI & 860 & 1045 & 540 & 350 & 245 & 175 & 120 & 0.52 & 2.75 & 3.53 & 2.00 \\
PII & 970 & 900 & 390 & 235 & 170 & 120 & 105 & 0.43 & 3.59 & 4.80 & 2.00 \\
PIII & 875 & 990 & 480 & 290 & 220 & 140 & 120 & 0.48 & 3.05 & 3.90 & 1.70 \\
\hline
\end{tabular}




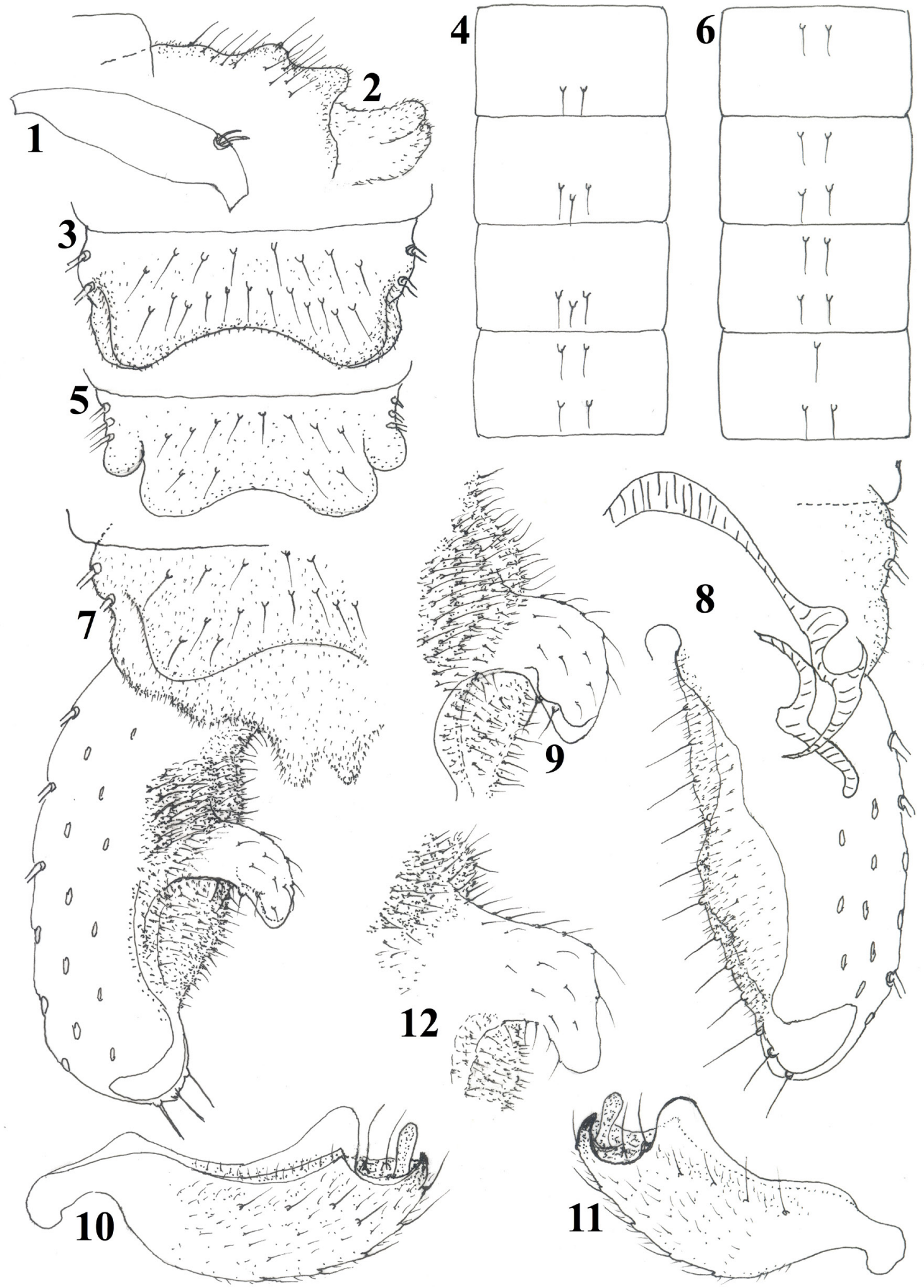

Figures 1-12. Male adult of Cricotopus spp. C. latellai sp. n.: 1, tarsomere 3 with sensilla coeloconica; 2, tergite IX, lateral; 3, tergite IX, dorsal; 4, distribution pattern of setae on median area of tergites II-V. C. mantetanus: 5, tergite IX, dorsal; 6 , distribution pattern of setae on median area of tergites II-V. C. latellai sp. n.: 7-8, hypopygium in dorsal and ventral view; 9, inferior volsella, dorsal; 10, left gonostylus, dorsal, at right angle; 11, right gonostylus, dorsal, at acute angle. C. mantetanus: 12 , inferior volsella, dorsal. 


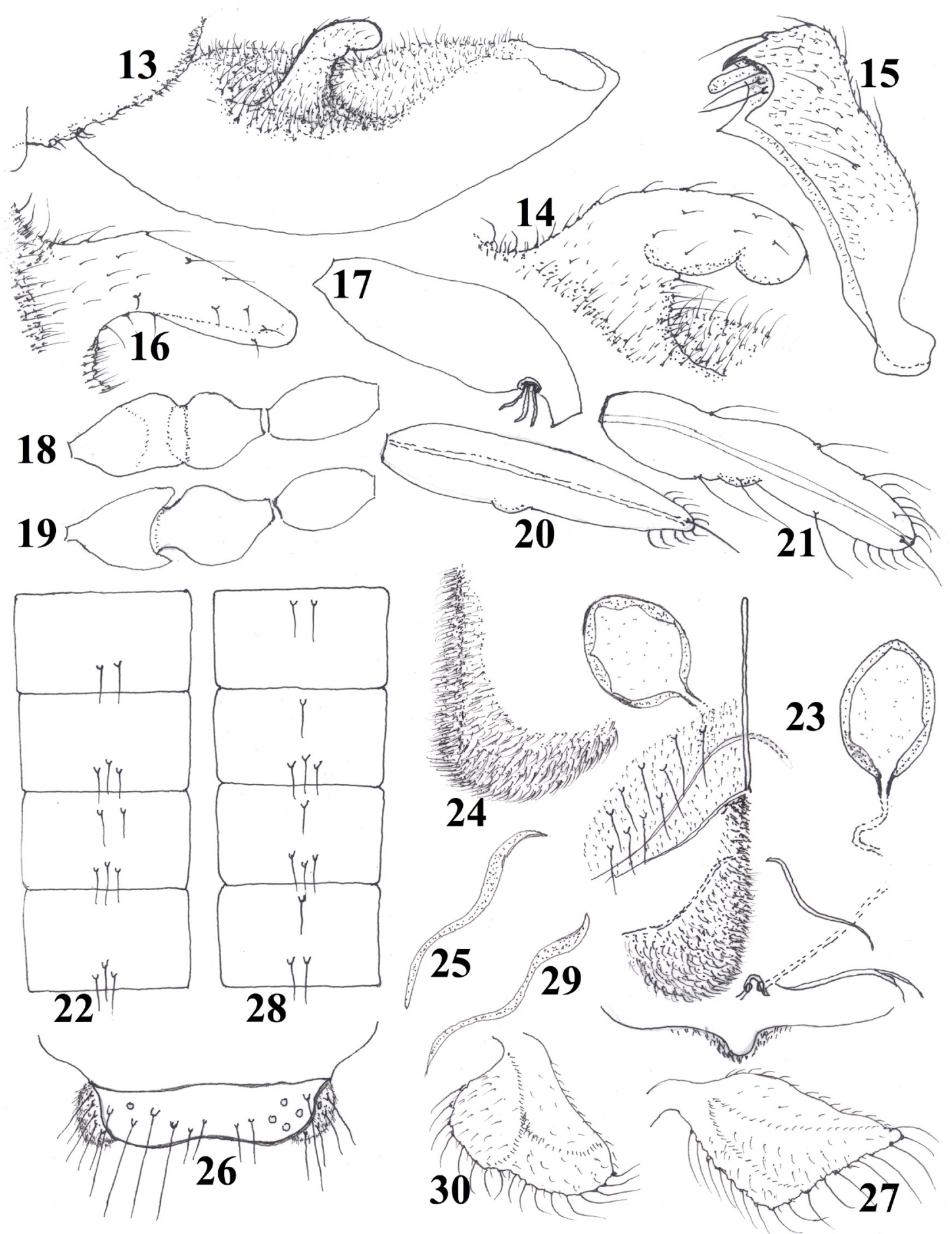

Figures 13-30. Male and female adults of Cricotopus spp. C. latellai sp. n., male adult: 13, gonocoxite and inferior volsella, lateral; 14, inferior volsella, lateral; 15, gonostylus, lateral. 16, C. mantetanus: inferior volsella, lateral. $C$. latellai sp. n., female adult: 17, palpomere 3 with sensilla coeloconica; 18-19, antenna, segments 1-3, two aspects; 2021 , last flagellomere, two aspects; 22, distribution pattern of setae on median area of tergites II-V; 23, genitalia, ventral and dorsal view with gonapophysis VIII, sternite VIII and seminal capsules; 24, dorsomesal and ventrolateral lobes; 25, apodeme lobe; 26, tergite IX, dorsal; 27, cercus. C. mantetanus: 29, apodeme lobe; 30, seminal capsule. 


\section{Female adult}

$(\mathrm{n}=3: 2$ pharate adults +1 adult; Figs 17-27)

Colouration as in the male adult except for the antennae, which are dark brown to blackish. Segments 1-5 of antenna brown with blackish apex, last flagellomere entirely blackish. Total length (TL) 4.20-4.50 mm. Wing length (WL) 2.20-2.30 $\mu \mathrm{m} . \mathrm{TL} / \mathrm{WL}=1.85-1.90$. Head: eyes hairy; temporal setae 8-9 including 5-6 inner and 3 outer verticals. Clypeus rectangular with $26-28$ setae in 4-5 rows. Palp 5-segmented, length $(\mu \mathrm{m})$ of segments: 40, 55, 50, 55, 125-130; palpomere 3 (Fig. 17) truncate apically and bearing 3 sensilla coeloconica placed distally. Antenna (Figs 18-21) 6-segmented, 365-385 $\mu \mathrm{m}$ long, segments 1 and 2 (Figs 18-19) fused; segments 3-5 together $150 \mu \mathrm{m}$ long and sub-equal (about $50 \mu \mathrm{m}$ each), ultimate flagellomere (Figs 20-21) about $120 \mu \mathrm{m}$ long, moderately clubbed and bearing a distinct small projection placed medially, distal part with 1 preapical seta and a tuft of curved setae including several sensilla chaetica; antennal groove restricted to last flagellomere. AR 0.46. Thorax: chaetotaxy as in the male; wing: distribution of setae on veins as in the male, squama with 11-13 setae in 1 row. Abdomen. Distribution pattern of setae on median area of tergites II-V as illustrated in Fig. 22: tergite II (2 setae distally), III (3 setae distally), IV (5 setae, 2 anteriorly and 3 distally, V (3 setae distally). Genitalia in dorsal and ventral view as illustrated in Figs 23-26. Notum about 100-110 $\mu \mathrm{m}$ long, rami indistinct. Sternite VIII with 22-24 setae (11-12 on each side of the notum). Gonapophysis VIII (Figs 23-25). Dorsomesal lobe uniformly linear; ventrolateral lobe broad and slightly projecting posteriorly; apodeme lobe undulating three times from base to apex. Seminal capsules 100-105 $\mu \mathrm{m}$ maximum length, $70 \mu \mathrm{m}$ maximum width, sub-oval with narrowed tip and well sclerotized laterally. Spermathecal ducts with loops and separate openings. Tergite IX (Fig. 26) nearly semi-circular and distinctly divided on its posterior part into two large rounded lobes, with 14 setae including 10 placed laterally (5 on each side) and 4 markedly shorter placed medially. Gonocoxite (Fig. 26) broadly globular, bearing 6-7 short setae. Cercus (Fig. 27) normally developed and narrowed distally.

\section{Male pupal exuviae}

$(\mathrm{n}=15: 7$ males, 8 females; Figs 31-36, 39-43)

Colouration contrasting brownish to dark brown with blackish cephalothorax. Frontal apotome with dense wrinkles and granulation; cephalothorax brown to dark brown with blackish anteromedian area, densely wrinkled and granulose, granulation and wrinkles strongly covering the anteromedian area including the thoracic suture and $\mathrm{Dc}_{1}-\mathrm{Dc}_{2}$ zone, granulose area along the thoracic suture reaching $\mathrm{Dc}_{3}-\mathrm{Dc}_{4}$ zone, posteromedian area less granulose, presence of a characteristic transversal posteromedian blackish shading extending between $\mathrm{Dc}_{3}-\mathrm{Dc}_{4}$ and base of wing sheath. Base of wing sheath covered with blackish bow-like shading. Abdomen including anal segment brown to dark brown; dark brown apophyses distinctly present on segments I/II-VII; muscles marks distinct on segments I-VIII.

Total length 3.60-4.10 mm. Frontal apotome (Fig. 31) distinctly domed with dense granulation, frontal setae bristle-like, inserted on prefrons ventral to antennal sheaths, $45 \mu \mathrm{m}$ long and separated by only $30 \mu \mathrm{m}$. Thorax (Figs 32-36). Antepronotals 3 including 2 median anteporontals (130 and $150 \mu \mathrm{m}$ long) and 1 lateral antepronotal $60 \mu \mathrm{m}$ long; 1 prealar 100-110 $\mu \mathrm{m}$ long; precorneals sub-equal (180$190 \mu \mathrm{m}$ long); dorsocentrals all seta-like, $\mathrm{Dc}_{1}$ and $\mathrm{Dc}_{2}$ sub-equal (110-120 $\mu \mathrm{m}$ long), $\mathrm{Dc}_{3}$ and $\mathrm{Dc}_{4} 40$ $\mu \mathrm{m}$ long; distance between $\mathrm{Dc}_{2}$ to $\mathrm{Dc}_{3} 150 \mu \mathrm{m}, \mathrm{Dc}_{1}$ is placed close to $\mathrm{Dc}_{2}, \mathrm{Dc}_{3}$ and $\mathrm{Dc}_{4}$ close to one another. Thoracic horn (Figs 33-36) foliate to ellipse shaped with narrowing distal part, toothed apically and distally (mainly on one side), teeth are often distinctly blunt apically. Abdomen. Armament and distribution pattern of patches of spines and points, chaetotaxy and lateral setation of abdominal segments as illustrated in Figs 39-43. Distribution of lateral setae on segments I-VIII: I (2), II-VIII (3). Tergite I bare. Transverse posterior margin of tergite II armed with 1-2 rows of orally projecting hooks, which occupy about $80 \%$ of segment width. Anteromedian patches of spines present on tergites III-V (Figs 39, 41), laterally extensive and becoming diamond-like to nearly semi-circular on tergite VI (Figs. 39, 41). Posteromedian transverse patches of spines present on tergites III-VI (Figs $39,41)$ not interrupted medially, gradually more extensive laterally and almost reaching muscles marks, size of spines mostly similar. Posteromedian transverse rows of orally projecting spines (Figs 39, 41) restricted to tergites III-V, occupying 75 to $80 \%$ of segments width. Pedes spurii B absent. Pedes spurii A present on sternites IV-VI. Armament absent on sternites I-VIII; field of shagreen and points present on anteromedian area of sternites III-VI; posterior transverse rows of spinules present on sternites V-VI, occasionally with a distinct median patch of small spines on sternite VI (Figs 39, 43). Apophyses markedly distinct on tergites I/II-VIII (Figs 28, 80). Anal segment (Figs $40,42)$ 200-220 $\mu \mathrm{m}$ long and $300 \mu \mathrm{m}$ maximum 


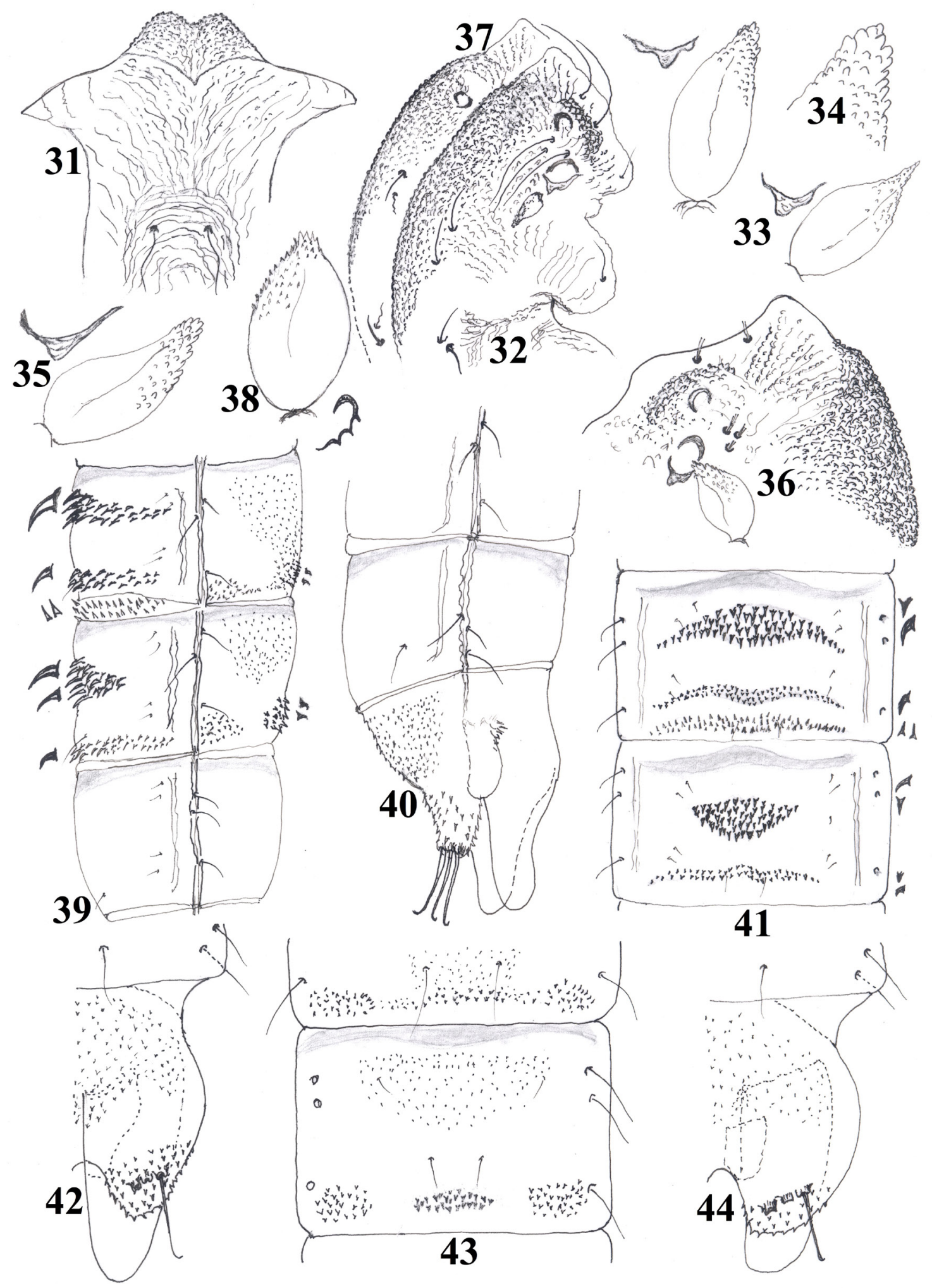

Figures 31-44. Cricotopus spp., male pupal exuviae. C. latellai sp. n.: 31, frontal apotome; 32, cephalothorax, chaetotaxy and granulation; 33-35, thoracic horn, three aspects; 34, thoracic horn, details of apical part; 36, cephalothorax, details of anteromedian area. C. mantetanus: 37, cephalothorax with dorsocentrals; 38, thoracic horn. C. latellai sp. n.: 39, armament and chaetotaxy of abdominal segments V-VII with details of the hook rows on tergites (left) and sternites (right); 40, lateral view of segments VII-VIII and anal segment; 41, armament of tergites V-VI (dorsal view) with median patch of spines and details of the hook rows; 42, anal lobe, right half, dorsal; 43, ventral view of sternites $\mathrm{V}$ (distal part) and VI (posteromedian patch of spines); C. mantetanus: 44, anal lobe, right half, dorsal. 
width, slightly narrowing distally, apical area with small spines extending well above insertion of anal macrosetae. Macrosetae about $100 \mu \mathrm{m}$ long, stout, pin-shaped and slightly curved apically. Genital sac (Fig. 42) 180-190 $\mu \mathrm{m}$ long, narrowed apically and overreaching apical margin of anal lobe by 65 $70 \mu \mathrm{m}$.

\section{Final instar larvae}

$(\mathrm{n}=3$, Figs $45-49) ; 2$ of the 3 examined larvae were attached to a pharate pupa.

Total length 3.90-4.00 mm, maximum width 0.5$0.6 \mathrm{~mm}$. Colouration contrasting pale greenish to blackish. Head (Fig. 45) blackish with a markedly transparent circular area (clearly visible in lateral view) placed on each side below base of antenna; proximal part of head capsule contrasting brown to dark brown including antennae and epipharyngeal region; mentum totally blackish; anteromedian area of clypeus densely covered with granulation. Thorax, abdomen and anal segment greenish.

Head illustrated in lateral view (Fig. 45). Eye spots broadly circular; clypeus (Fig. 46) nearly trap- ezoidal, densely granulose on lateral parts; frontal apotome (Fig. 46) $370 \mu \mathrm{m}$ long, with 3 pairs of lateral setae, median and distal setae are setae-like and about $200 \mu \mathrm{m}$ long, proximal setae are bristlelike and shorter (about $90 \mu \mathrm{m}$ long). Antenna (Fig. 47) 5-segmented, $95 \mu \mathrm{m}$ long; basal segment about $55 \mu \mathrm{m}$ long and $20 \mu \mathrm{m}$ maximum width, AR 1.351.45 ; ring organ placed about $1 / 4$ distance from base of antenna, accessory blade markedly overreaching fifth segment as in C. storozhenkoi (Makarchenko \& Makarchenko 2016, Fig. 27). Mandible (Fig. 45) with 6-7 teeth, apical tooth nearly as long as combined length of two first lateral teeth. Mentum (Figs 45, 48) composed of 1 median large tooth and 5-6 pairs of lateral teeth, apical pair of teeth smooth and domed, first and second lateral teeth distinctly fused at base. Procercus (Fig. 49) bilobed distally with 6 long setae, dorsal seta about $100 \mu \mathrm{m}$ long.

\section{Taxonomic position}

C. latellai sp. n. can be separated from its morphologically most similar European species C. mantetanus by a combination of characters.

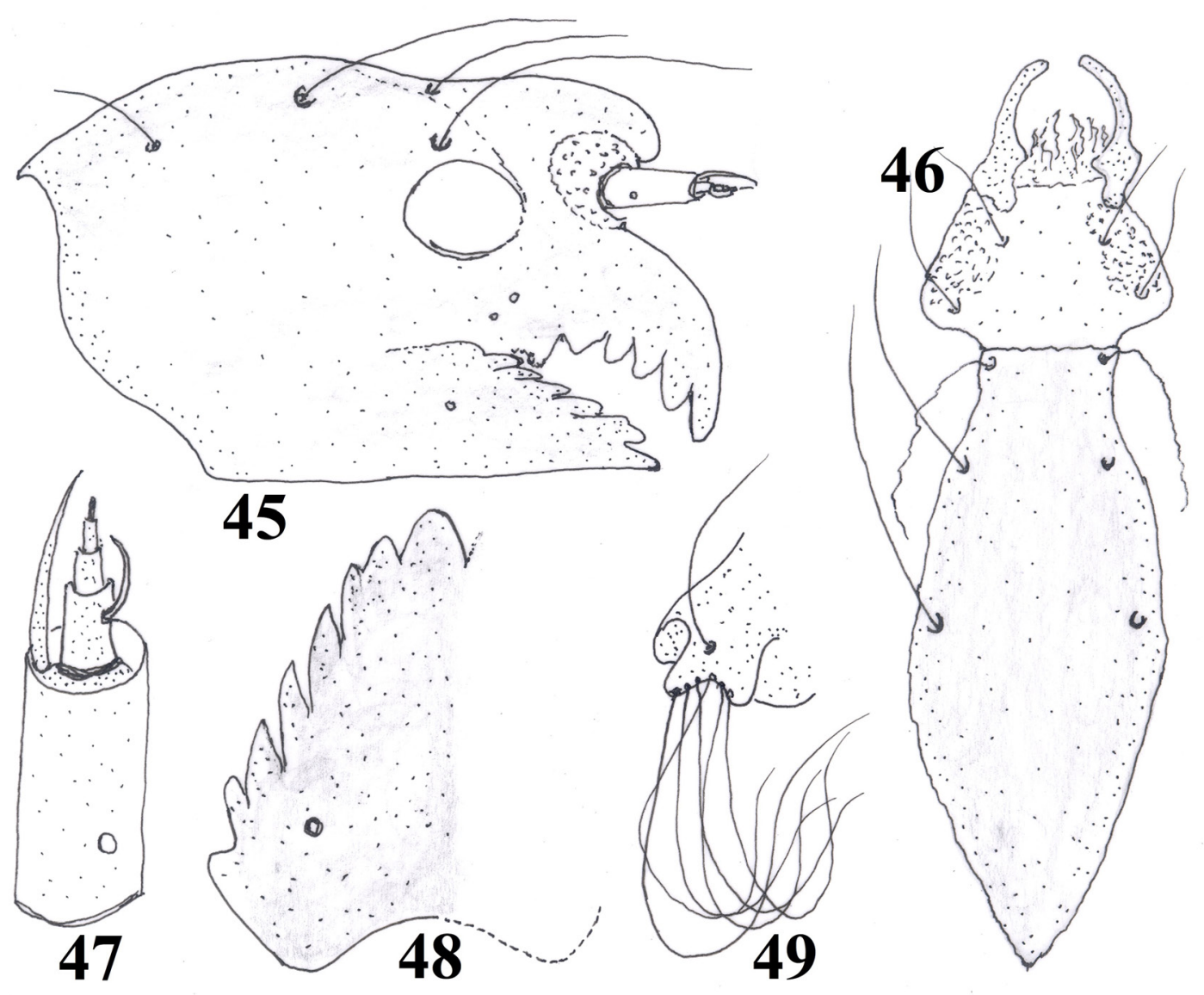

Figures 45-49. Larva of Cricotopus latellai sp. n. 45, head, right side, lateral view; 46, head capsule, dorsal; 47, antenna; 48 , mentum, half part; 49 , procercus with dorsal and anal setae, lateral view. 
In the male adult: median area of tergites III-IV each with 3 distal setae (Fig. 4), while there is 4 setae ( 2 anterior and 2 posterior) in C. mantetanus (Fig. 6); tergite IX differently shaped in lateral and dorsal view (Figs 2-3) than in C. mantetanus (Fig. 5).

In the pupal exuviae: granulation on cephalothorax covering the entire anteromedian area and thoracic suture (Fig. 32), is differently figured in C. mantetanus (Fig. 37); dorsocentrals are all setae-like; thoracic horn foliate to ellipsoidal and narrowed distally (Figs 33-34); posteromedian area of sternites VI with a patch of small spines (Fig. 43).

\section{Additional remarks}

According to the previously provided key for known male adults and pupal exuviae from the Tyrrhenian Region (Moubayed-Breil 2016), C. latellai sp. n. keys near $C$. mantetanus and $C$. storozhenkoi based on the following combination of characters:

outer margin of inferior volsella is rounded for $C$. latellai sp. n. and C. storozhenkoi,

shape of the thoracic horn for C. latellai sp. n. and C. mantetanus, while a nearly similar shape of anal lobe is observed in both $C$. latellai sp. n. and $C$. mantetanus.

Consequently, the main differentiating morphological features found in the male adults and pupal exuviae of the tremulus-group can be supplemented based on the combination of characters summarized in the following key of known species from the Tyrrhenian Region.

\section{Male adults}

1. Inferior volsella pointing downwards at an acute angle, narrow and finger-like (Moubayed-Breil 2016, Fig. 47; Casas \& Vilchez-Quero 1992, Figs 1A-B), outer margin not gradually or abruptly bent downwards ....... C. nevadensis (Spain, Portugal)

- Inferior volsella not pointing downwards at an acute angle, not narrow and finger-like, outer margin gradually (Figs 7, 9) or abruptly (Fig. 12) bent downwards ................................. 2

2. Outer margin of inferior volsella abruptly bent downwards medially at a right angle and with 2 strong dorsal setae on outer edge (Fig. 12; Moubayed-Breil 2016, Figs 6, 8-9) C. mantetanus (France)

- Outer margin of inferior volsella rounded and bent gradually downwards, lacking strong dorsal setae on outer edge (Figs 7, 9; Moubayed-Breil 2016, Figs 43, 45)
3. Gonostylus with large, broad, apicaly rounded, strongly projecting crista dorsalis (Figs 10-11); median area of tergites III-IV each with 3 setae placed distally (Fig. 4) .... C. latellai (France, Italy)

- Gonostylus not as described above, with small crista dorsalis (Moubayed-Breil 2016, Figs 11, 43); median area of tergites III-IV each with 5 setae (2 proximal, 3 distal) (Moubayed-Breil 2016, Fig. 5) or tergites III and IV respectively with 4 setae (1 proximal, 3 distal) and 5 setae (2 proximal, 3 distal) (Moubayed-Breil 2016, Fig. 41) 4

4. Gonostylus with rounded posterior margin, crista dorsalis short, tooth-like with rounded apex (Moubayed-Breil 2016, Fig. 11); median area of tergites III-IV with 5 dorsal setae (2 proximal, 3 distal) (Moubayed-Breil 2016, Fig. 5)

C. tremulus (widespread Holarctic species)

- Gonostylus with sinuous posterior margin, crista dorsalis tooth-like with pointed apex (MoubayedBreil 2016, Fig. 43); median area of tergite III with 4 setae (1 proximal, 3 distal) and tergite IV with 5 setae (2 proximal, 3 distal) (Moubayed-Breil 2016, Fig. 41)............. C. royanus (France, Italy)

\section{Pupal exuviae}

1. Thoracic horn over three times as long as broad, elongated to lobe-like, densely to weakly toothed distally on one side or entirely smooth; median patch of spines on tergite VI diamond-like or spinning-top-like; anal lobe broadly rounded apically, densely covered with rows of small spines placed near the posterior margin

2

- Thoracic horn about twice as long as broad, lobe-like or foliate to ellipse-like, entirely smooth or distinctly toothed distally and apically; median patch of spines on tergite VI rounded or nearly semi-circular; anal lobe narrowing distally (Fig. 42 ), weakly to moderately covered with small spines (Figs 42, 44) ................................... 3

2. Granulation on cephalothorax only covering the anterior part of thoracic suture, sparsely covering the anteromedian area; thoracic horn moderately toothed medially, distally and apically on one side; median patch of spines on tergite VI spinning toplike (Moubayed-Breil 2016, Fig. 77) .............. C. royanus

- Granulation on cephalothorax sparse and restricted to the anteromedian area close to the thoracic suture; thoracic horn smooth or only toothed apically, occasionally toothed pre-apically on one side; median patch of spines on tergite VI sub-oval to nearly diamond-like C. nevadensis 
3. Granulation on cephalothorax restricted to the anteromedian area located close to the thoracic suture; thoracic horn balloon-like and entirely smooth (Hirvenoja, 1973, Fig. 113.3); C. tremulus

- Granulation on cephalothorax covering at least the anteromedian area and the thoracic suture (Figs 32, 37); thoracic horn foliate to ellipsoidal in shaped and bearing teeth at least apically (Figs 33$35,38)$. 4

4. Granulation on cephalothorax covering the anteromedian area and thoracic suture but not reaching the $\mathrm{Dc}_{3}-\mathrm{Dc}_{4}$ zone (Fig. 37); thoracic horn ellipse shaped (Fig. 38), toothed apically and medially on one side; median patch of spines on tergite VI diamond-like; anal lobe weekly covered with small spines (Fig. 44) C. mantetanus

- Granulation on cephalothorax densely covering the antero- and posteromedian area and the thoracic suture, reaching the $\mathrm{Dc}_{3}-\mathrm{Dc}_{4}$ zone (Fig. 32); thoracic horn foliate to ellipsoidal (Figs 33-35) with narrowing distal part, apex of teeth are often smooth (Fig. 34); median patch of spines on tergite
VI diamond-like to semi-circular (Fig. 41); anal lobe moderately covered with small spines (Fig. 42).................................. C. latellai

\section{Ecology and geographical distribution}

Localities where the larval, imaginal and pupal material of $C$. latellai $\mathrm{sp}$. $\mathrm{n}$. were collected consist of pristine epirhithral sections located in middle and high sectors of glacial streams (upper basin of the River Po, northwestern Italy, Fig. 50). Environmental data of water are: crystalline to moderately calcareous water, conductivity (about 20-30 $\mu \mathrm{S} / \mathrm{cm}$ for dolomitic areas of the upstream of the Po River; $95-100 \mu \mathrm{S} / \mathrm{cm}$ for the calcareous upstream of the Casterino stream); temperature $8-12{ }^{\circ} \mathrm{C}$ during late spring and summer. Emergence is observed in June and July but apparently extends to late summer. Geographical distribution (Fig. 51) is delimited by the eastern limit of the Tyrrhenian Region, which covers both the Italian and French Maritime Alps. Moreover, C. latellai sp. n. belongs to a relict glacial element, which is believed to characterize the Tyrrhenian continental Province where other Tyrrhenian elements have previously been documented by Moubayed-Breil \& Ashe (2016) and

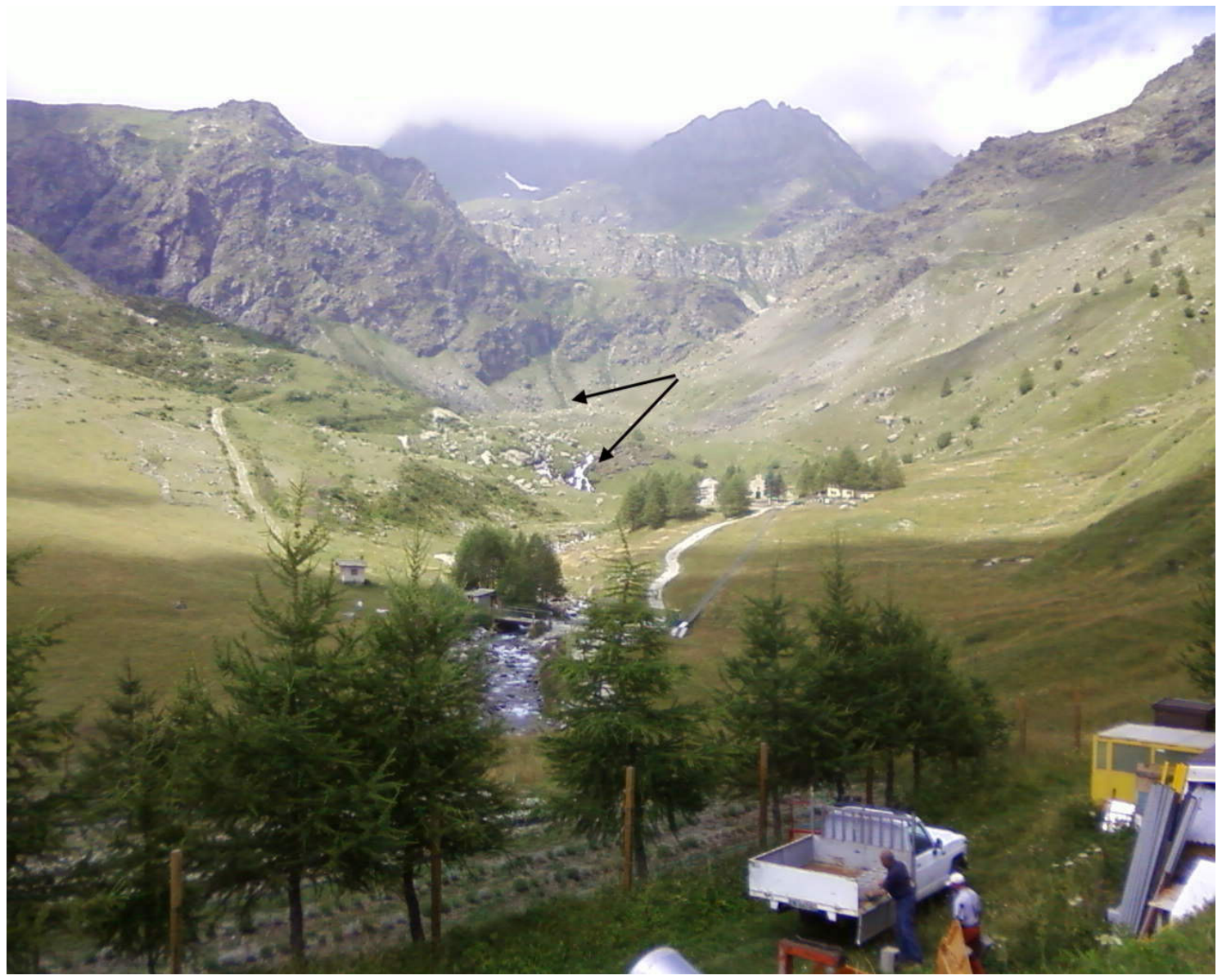

Figure 50. Riffles and waterfalls (altitude 1700-1800 m) delimited by the upper basin of the River Po at 'Pian del Re', Alpi Marittime, north-western Italy. Photo J. Moubayed-Breil, 09.07.2017. 


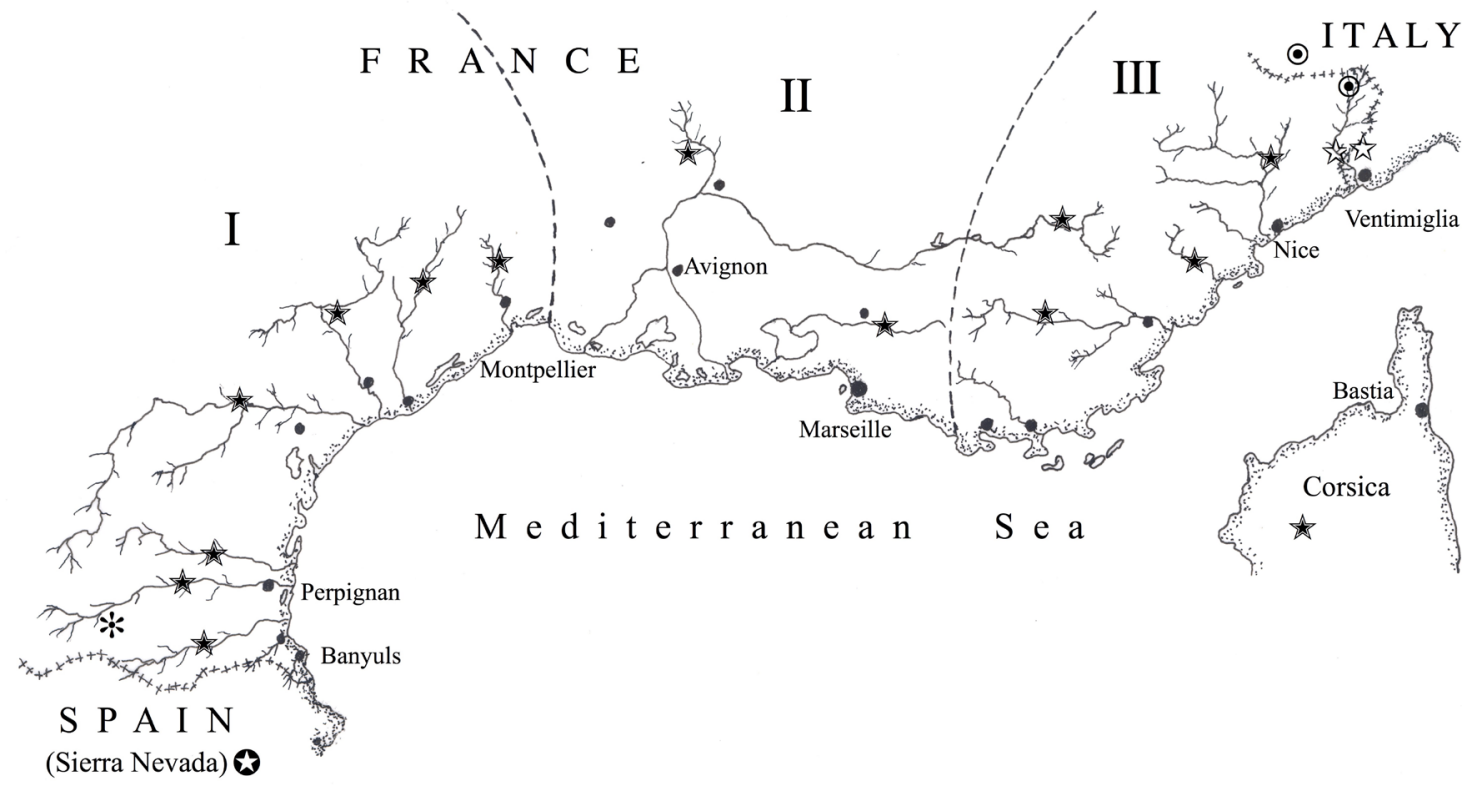

Figure 51. Geographical distribution of the five currently known Cricotopus species (tremulus-group) in the Tyrrhenian Region delimited by continental France, Italy, Spain and Corsica: C. latellai sp. n. ○, C. mantetanus *, C. nevadensis $\boldsymbol{\oplus}$, C. royanus «, C. tremulus $\star$.

Moubayed-Breil \& Orsini (2016). This highlights the importance of some high local glacial mountain ranges in the Mediterranean Region where constructive plans for conservation and preservation of autochthonous glacial relic species must be implemented. Such relic species are considered as biogeographically representative and biological indicators of global warming and climate change.

Associated species in the same habitat to C. latellai sp. n. include: Boreoheptagyia legeri (Goetghebuer, 1933); Diamesa cinerella (Meigen, 1835); D. hamaticornis Kieffer, 1924; D. latitarsis (Goetghebuer, 1921); D. thomasi Serra-Tosio, 1970; $D$. tonsa (Haliday, 1856); D. zernyi Edwards, 1933; Pseudodiamesa branickii (Nowicki, 1873); P. nivosa (Goetghebuer, 1928); Cricotopus (Paratrichocladiua) spiesi (Ashe \& O'Connor, 2013); Eukiefferiella ilkleyensis (Edwards, 1929); E. fittkaui Lehmann, 1970; E. minor (Edwards, 1929); Krenosmittia camptophleps (Edwards, 1929); Limnophyes gelasinus Sæther, 1970; Orthocladius ruffoi Rossaro \& Prato, 1991; Pseudorthocladius curtistylus (Goetghebuer, 1921); Thienemannia corsicana Moubayed-Breil, 2013; T. gracilis Kieffer, 1909; T. spiesi Moubayed-Breil \& Ashe, 2016 and Tvetenia bavarica (Goetghebuer, 1934).

\section{Acknowledgements}

We are grateful to the organizers of the $20^{\text {th }}$ International Symposium on Chironomidae (Trento, Italy, July 2017) who supported us in making collections in the Italian Alpine Region, which result- ed in the discovery and description of Cricotopus latellai $\mathrm{sp}$. n. Special thanks are also due to staff of the Maritime Italian Park for providing the authorization to collect material in the protected area of 'Parco del Alpi Marittime'.

\section{References}

Andersen, T., Sæther, O.A., Cranston, P.S. and Epler, J.H. 2013. The larvae of Orthocladiinae (Diptera: Chironomidae) of the Holarctic Region - eys and diagnoses. - Insect Systematics \& Evolution, Supplement 66: 189-235.

Ashe, P. and O'Connor, J.P. 2012. A World Catalogue of Chironomidae (Diptera). Part 2. Orthocladiinae. Irish Biogeographical Society \& National Museum of Ireland, Dublin. 1-968.

Casas, J.J. and Vilchez-Quero, A. 1992. Cricotopus (Cricotopus) nevadensis sp. n. (Diptera, Chironomidae) from Sierra Nevada (southern Spain). - Hydrobiologia 230: 71-78. https:// doi.org/10.1007/BF00006127

Coffman, W.P., Cranston, P.S., Oliver, D.R. and Sæther, O.A. 1986. The pupae of Orthocladiinae (Diptera: Chironomidae) of the Holarctic Region-keys and diagnoses. In Wiederholm, T. (ed.): Chironomidae of the Holarctic Region. Keys and diagnoses. Part 2 - Pupae. - Entomologica Scandinavica, Supplement 28: 147-296.

Cranston, P.S., Oliver, D.R. and Sæther, O.A. 1989. The adult males of Orthocladiinae (Diptera: Chironomidae) of the Holarctic Region - 
Keys and diagnoses. In: Wiederholm, T. (ed.): Chironomidae of the Holarctic region. Keys and diagnoses. Part 3 - Adult males. - Entomologica Scandinavica, Supplement 34: 164-352.

Hirvenoja, M. 1973. Revision der Gattung Cricotopus van der Wulp und ihrer Verwandten (Diptera, Chironomidae). - Annales Zoologici Fennici 10: 1-363.

Lencioni, V., Marziali, L. and Rossaro, B. 2012. Chironomids as bioindicators of environmental quality in mountain springs. - Freshwater Science 31(2): 525-541. https://doi. org/10.1899/11-038.1

Makarchenko, E.A., and Makarchenko, M.A. 2016. Two new species of Cricotopus (s. str.) tremulus-group (Diptera, Chironomidae, Orthocladiinae) from the Russian Far East. - Euroasian Entomological Journal 15 (1): 94-102.

Moubayed, Z. and Hirvenoja, M. 1986. Les Chironomidae du Liban. IV. Cricotopus (Cricotopus) levantinus n. sp. (Diptera: Chironomidae, Orthocladiinae). - Bulletin de la Société d'Histoire Naturelle de Toulouse 122: 169-173.

Moubayed-Breil, J. 2016. On the genus Cricotopus v. d. Wulp, 1874 (tremulus-group) from continental France and Corsica with description of $C$. mantetanus sp. n. and C. royanus sp. n. [Diptera, Chironomidae, Orthocladiinae]. Ephemera 17(2): 71-104.

Moubayed-Breil, J. In press. Propsilocerus seezanus sp. n., a new alpine element occurring in the oligotrophic high mountain Lake Seez, Eastern France (Diptera, Chironomidae,
Orthocladiinae). - Euroasian Entomological Journal.

Moubayed-Breil, J. and Ashe, P. 2011. Taxonomic notes on Cricotopus levantinus Moubayed \& Hirvenoja and Limnophyes gelasinus Sæther [Diptera, Chironomidae]. - Ephemera 12(1): 7-15.

Moubayed-Breil, J. and Ashe, P. 2016. New records and additions to the database on the geographical distribution of some threatened chironomid species from continental France [Diptera, Chironomidae]. - Ephemera 16(2): 121-136.

Moubayed-Breil, J. and Orsini, A. 2016. On the genus Potthastia Kieffer, 1922 from Corsica and continental France with description of three new species [Diptera, Chironomidae, Diamesinae]. - Ephemera 17(1): 1-36.

Sæther, O.A. 1977. Female genitalia in Chironomidae and other Nematocera: morphology, phylogenies, keys. - Bulletin of the Fisheries Research Board of Canada 197: 1-209.

Sæther, O.A. 1980. Glossary of chironomid morphology terminology (Diptera: Chironomidae). - Entomologica Scandinavica, Supplement 14: $1-51$.

Sæther, O.A. and Spies, M. 2013. Fauna Europaea: Chironomidae. In P. Beuk \& T. Pape (eds): Fauna Europaea: Diptera Nematocera. Fauna Europaea version 2.6. Internet database at http://www.faunaeur.org [accessed February 2015]. 